\title{
EDITORIAL
}

\section{Prospects and promises in the study of resilience}

\author{
DANTE CICCHETTI ${ }^{a}$ AND NORMAN GARMEZY ${ }^{b}$ \\ ${ }^{\circ} \mathrm{Mt}$. Hope Family Center, University of Rochester; and ${ }^{b}$ University of Minnesota
}

Examinations of risk and psychopathology across the life course all too often portray the developmental process as somewhat deterministic, resulting in maladaptive and adverse outcomes. Studies ranging from genetic and biological predispositions to pathology, to assaults on development associated with inadequate caregiving, graphically convey the multiplicity of risks that eventuate in psychopathology. Thus, it is especially refreshing to explore the more optimistic component of the psychopathology-risk equation, namely, resilience. What individual, familial, or societal factors stem the trajectory from risk to psychopathology, thereby resulting in adaptive outcomes even in the presence of adversity? It is the answer to this query that the contributors to this Special Issue of Development and Psychopathology have directed their energies toward elucidating.

This Special Issue may well be a "first" in its presentation of a group of articles detailing research strategies and empirical findings that are focused on the construct of "resilience." Of course, a significant and il-

\footnotetext{
We express our gratitude to the William T. Grant Foundation, the John D. and Catherine T. MacArthur Foundation, the National Institute of Mental Health, and the Spunk Fund, Inc., for their generous support of our work on this project. Dante extends his special thanks to Marianne Gerschel for her encouragement and support of this work. Norm is grateful to his colleagues at the University of Minnesota, Drs. Ann Masten and Auke Tellegen.
}

lustrious history of research detailing precursors to as well as contemporary patterns of stress resistance was necessary before work on resilience could proceed (see, e.g., Garmezy \& Masten, in press; Garmezy \& Rutter, 1983; Luthar \& Zigler, 1991; Masten, 1989, for reviews). In fact, in many early studies, evidence of adaptive behavior was present, but the nomenclature for labeling findings as evidence for resilience had not yet emerged. Nonetheless, the roots of work on resilience can be traced back to many prior publications in highly diverse areas. Specifically, investigations of schizophrenia, poverty, and response to trauma all predated work on resilience, but all uncovered findings that are relevant to the construct of resilience.

The literature on schizophrenia can be viewed as one founding base in providing exemplars of resilience. However, because investigators of severely psychotically disordered patients were more invested in understanding maladaptive behavior, the subset of patients who evidenced recovery and adaptive patterns were considered to be somewhat atypical and afforded little attention. In fact, prior to the 1920 s and continuing through the 1940s, schizophrenia was viewed as a disease process that typically culminated in an ever-growing deterioration of functioning (Bleuler, 1950; Kraepelin, 1919). This pervasive belief was assaulted by observations of clinicians and researchers that revealed a divergent pre- 
morbid history and illness course in a subset of schizophrenics. Typically, schizophrenics who evidenced a less severe course of illness were characterized by a premorbid history of competence in work, social relations, marital status, and capacity to fulfill responsibility. The adaptive early histories, manifest signs of premorbid competence, and differentiated symptom patterns evidenced by these "atypical" schizophrenics resulted in the creation of a dichotomy between the more common "chronic" longterm pattern of schizophrenia and the briefer and more adaptive life-history pattern that led to a designation of the "reactive" type of schizophrenia (Garmezy, 1970; Zigler \& Glick, 1986). The reactive pattern also was frequently associated with recovery.

Although resilience was not a part of the descriptive picture of these atypical schizophrenics, the behavioral and historical pattern of these patients was an early example of what today might be identified as signs of premorbid resilience indicators. As interest in resilience burgeoned, the adaptive patterns and recovery of reactive schizophrenics commanded increased interest and was factored into models of resilience.

Resilience also was evident in other situations associated with exposure to chronic stress. Poverty inevitably provides a plenitude of stressors, yet the literature reveals the patterning of positive behaviors in many children exposed to economic and/or social deprivation. Examples include Elder's (1974) Children of the Great Depression; Festinger's (1983) No One Ever Asked Us, detailing the outcomes in adulthood of young children reared in foster homes and institutional settings; Pavenstedt's (1965) comparison of the adaptations of children reared in upper-lower and very low-lower social environments; Long and Vaillant's (1984) follow-up study of Glueck and Glueck's (1950) investigations of delinquency during the 1940s; and the Kandel et al. (1988) study of a Danish cohort that demonstrated the avoidance of potential delinquency among children with severely criminal fathers.

Finally, historical instances of adaptive functioning in individuals exposed to trauma have contributed to the foundation on which theories and investigations of resilience have been built. Specifically, these events include children exposed to the "cauldron of turmoil" in Northern Ireland (Harbison, 1983) who have remained resilient and adaptable and have coped surprisingly well with Northern Ireland's "troubles" (p. 154), children of the Holocaust grown to adulthood (Epstein, 1979; Moskovitz, 1983), and the "malleability" of poor and minority children (Clark, 1983; Comer, 1980; Gallagher \& Ramey, 1987; Monroe \& Goldman, 1988; Neisser, 1986). Children exposed to disasters provide a supplemental portrait of the presence of "malleability" for some, but not for all, youngsters.

Thus, evidence for resilience can be found in early programs of research with psychopathological populations and in individuals exposed to extreme stress as well as in the functioning of those who experienced historical traumatic occurrences. The more contemporaneous roots of resilience can be traced to the seminal work of Garmezy and his colleagues (Garmezy, 1971; Garmezy \& Streitman, 1974). These writings were among the earliest examples of efforts to stress the importance of examining protective factors in "at-risk" populations, and they laid the groundwork for future work in the area of resilience.

Current efforts to understand the mechanisms and processes leading to resilient outcome have been facilitated by investigators conducting work within the arena of developmental psychopathology (Rutter, 1987). As the developmental perspective has assumed a more prominent role in psychopathology research, there has been a growing interest in the study of resilience. For example, the recognition of the diversity of developmental outcomes and the complexity of developmental pathways has led to a growing interest regarding the presence of successful adaptation despite adversity. In their exposition of the domain and boundaries of developmental psychopathology, Sroufe and Rutter (1984) not only addressed "the study of the origins and course 
of individual patterns of behavioral maladaptation" (p. 18), but also stressed the need to understand "patterns normally predictive of disorder but which for reasons to be discovered, do not do so with a particular subgroup of subjects [italics ours]" (pp. 18-19). Developmental psychopathologists believe that knowledge of normal development is necessary to understand deviations from normality and that, similarly, information obtained from studying atypicality enhances the understanding of normal development (Cicchetti, 1984, in press; Cicchetti \& Toth, 1991). Thus, developmental psychopathologists are as interested in highrisk individuals who do not manifest psychopathology as they are in individuals who develop a disorder (Sroufe \& Rutter, 1984). By uncovering the mechanisms and processes that lead to competent adaptation despite the presence of adversity, our understanding of both normal development and psychopathology is enhanced. Within this context, it is important that neither adaptive, maladaptive, nor resilient functioning be viewed as a static condition but, rather, as being in dynamic transaction with intraand extraorganismic forces (Cicchetti \& Schneider-Rosen, 1986).

Before. the construct of resilience can truly reap the rich promise that it holds for promoting our knowledge of development and psychopathology, however, a number of caveats must be articulated. It is our hope that the articles contained in this Special Issue will serve as an impetus to fostering theoretical and research gains. Currently, the popularity of resilience as a construct has exceeded the research output associated with it. As such, resilience is at risk for being viewed as a popularized trend that has not been verified through research and, thereby, in danger of losing credibility within the scientific community. To prevent this, it is imperative that theorists in the area of resilience devote equal effort to advancing the construct empirically.

Toward this goal, a number of issues must be addressed. Perhaps first and foremost, researchers must clearly operationalize their definition of resilience. At present, various researchers employ different definitions of resilience that can range from the absence of psychopathology in the child of a mentally ill parent to the recovery of function in a brain-injured patient. Definitional diversity results in sometimes disparate profiles of competent adaptation as well as in different estimates of rates of resilience among similar risk groups. Depending on how broad or conservative the definition of resilience is, vastly different conclusions can be drawn. While it may still be premature to agree on the definition of resilience, this may well be a future goal of investigators. In the interim, specifics on the operationalization of resilience need to be included in all research reports.

Related to the operationalization of resilience is the importance of recognizing that it is not a static trait. Rather, new vulnerabilities and/or strengths may emerge during developmental transitions throughout the life course as well as during periods of acute stress. To reflect the process of resilience, it will be increasingly necessary for investigators to observe children considered to be resilient over time. As an alternative to timeintensive longitudinal studies, a case can be made for the conduct of short-term studies that chart changes in life-span developmental trajectories (Garmezy, 1990). Specifically, the effect of a stressful major life event on positive or negative adaptation could be examined. Similarly, functioning during a life period generally considered to be stressful (e.g., adolescence) could provide important information on functioning.

The incorporation of a developmental perspective into work in this area also underscores the need to examine functioning across domains of development. While a child may appear to be adapting positively within the school arena if outcome measures focus solely on cognitive abilities, the same child may manifest impaired social relationships. Unless multiple domains of development are assessed, only a partial picture of adaptation can be formulated. This is especially problematic if significant maladaptation subsequently emerges, as it would appear to be an unexplained diver- 
gence when, in reality, the earlier portrayal of adaptive functioning was incorrect.

The range and degree of "risk" in studies of resilience also are great and raise an important issue. Investigators must be cautious that children who are labeled resilient are not simply children who have not been exposed to the stressor under investigation (cf. Richters \& Weintraub, 1990). For example, a child with a mother who has been depressed will not necessarily experience poor-quality caregiving. Moreover, the maternal depression may have been situationally based, and the child may not have inherited a genetic predisposition for depression. In a situation such as this, the child might be better classified as low risk than as resilient. The issue of magnitude of risk cannot be minimized, and risk should not be assumed merely in response to the presumed presence of a stressor. Rather, more comprehensive information on risk must be attained in all samples.

Finally, the very concept of resilience as "invulnerability" must be examined so as to avoid the perpetuation of two extreme and diametrically opposed views of development and psychopathology. The first, which Meehl (1973) decried, was referred to as the "spun glass theory of mind" and promoted the view that children are so fragile that even common everyday occurrences such as minor criticism or rejection could result in major trauma or even psychopathology. Conversely, it has been assumed that invulnerable children are somewhat herculean in their resistance to stress. As our knowledge has grown, we have come to realize that neither portrayal of functioning is wholly accurate. With regard to resilience, we believe that some individuals can maintain competent functioning despite an interfering emotionality. This conceptualization is important in its emphasis on the dialectic that exists between successful adaptation and the struggles associated with this process (cf. Jamison, 1993). By recognizing that even "resilient" children need support and may be vulnerable throughout their lives, we will be helping to ensure the provision of adequate and necessary services for these children. In fact, the very availability of support may be a critical component in the continued expression of resilience.

Despite the limitations associated with the aforementioned concerns, a growing literature does attest to the emergence of scientific interest in adaptive patterns of functioning in a substantial majority of individuals confronted by adverse events and circumstances. At the same time that the attractiveness of the construct is intriguing both scientists and practitioners, however, the stark reality remains that strongly supportive research studies that validate the antecedents to and the consequences of adaptive performance under stress continue to be far too rare. Without rigorously designed investigations, myth rather than knowledge will be promoted as a guide to action.

This issue of Development and Psychopathology may well serve as a beginning of the much needed research venture. The contributors to this Special Issue on resilience have been drawn from diverse areas. Their contributions are theory or review oriented in some instances and provide reports of ongoing research programs in others. Their range includes criticisms of the construct; reports of longer term major longitudinal studies; specific clinical disorders such as depression, bipolar disorder, and schizophrenia in mothers and their consequences for of fspring; risk factors in child maltreatment; reports on resilience in later adulthood and in the aged; the role of assortative mating and its consequences; adaptational patterns of minority adolescents; resilience in the context of community violence; and genetic factors in studies of children who are at risk.

If this issue can serve the role of bringing to readers of Development and Psychopathology the multiple contexts for the manifestation of resilient behaviors accompanied by reflections on theoretical issues associated with resilience, then we will be a step closer in the search for underlying processes and mechanisms that help to explain the attributes of stress resistance. The scientific search is a challenging one. It includes the 
garnering of knowledge on specific adaptational efforts of children, adolescents, and adults to meet the challenge of cumulative adversities in their lives, the consequences for children of being reared in multirisk families and the diversity of behavioral outcomes that typify such at-risk groups, and the integration of biological, psychological, and sociocultural influences into the quest for understanding the roots of resilience.

\section{References}

Bleuler, E. (1950). Dementia praecox or the group of schizophrenias (H. Zinkin, Trans.). New York: International Universities Press. (Original work published 1911)

Cicchetti, D. (1984). The emergence of developmental psychopathology. Child Development, 55, 1-7.

Cicchetti, D. (in press). Developmental psychopathology: Reactions, reflections, projections. Developmental Review.

Cicchetti, D., \& Schneider-Rosen, K. (1986). An organizational approach to childhood depression. In M. Rutter, C. Izard, \& P. Read (Eds.), Depression in young people, clinical and developmental perspectives (pp. 71-134). New York: Guilford Press.

Cicchetti, D., \& Toth, S. L. (1991). The making of a developmental psychopathologist. In J. Cantor, C. Spiker, \& L. Lipsitt (Eds.), Child behavior and development: Training for diversity (pp. 34-72). Norwood, NJ: Ablex.

Clark, R. M. (1983). Family life and school achievement: Why poor black children succeed or fail. Chicago: University of Chicago Press.

Comer, J. P. (1980). School power. New York: Free Press.

Elder, G. H., Jr. (1974). Children of the Great Depression. Chicago: University of Chicago Press.

Epstein, H. (1979). Children of the Holocaust. New York: Penguin Books.

Festinger, T. (1983). No one ever asked us. New York: Columbia University Press.

Gallagher, J. J., \& Ramey, C. T. (1987). The malleability of children. Baltimore, MD: Paul Brookes.

Garmezy, N. (1970). Process and reactive schizophrenia: Some conceptions and issues. Schizophrenia Bulletin, 2, 30-74.

Garmezy, N. (1971). Vulnerability research and the issue of primary prevention. American Journal of Orthopsychiatry, 41, 101-116.

Garmezy, N. (1990). A closing note: Reflections on the future. In J. Rolf, A. Masten, D. Cicchetti, K. Nuechterlein, \& S. Weintraub (Eds.), Risk and protective factors in the development of psychopathology (pp. 527534). New York: Cambridge University Press.

Garmezy, N., \& Masten, A. (in press). Chronic adversities. In M. Rutter, L. Hersov, \& E. Taylor (Eds.), Child and adolescent psychiatry (3rd ed.). Cambridge: Blackwell Scientific Publications.

Garmezy, N., \& Rutter, M. (Eds.). (1983). Stress, coping and development in children. New York: McGraw-Hill.
This is the challenge of the present and the future. The editors thank the authors of this Special Issue of Development and Psychopathology for beginning the tasks of advancing our knowledge of the antecedents and consequences of resilient functioning. If our search is successful, the implications for theory development, treatment provision, and policy initiatives are likely to exceed our expectations.

Garmezy, N., \& Streitman, S. (1974). Children at risk: The search for antecedents to schizophrenia. Part I: Conceptual models and research methods. Schizophrenia Bulletin, 8, 14-90.

Glueck, S., \& Glueck, E. (1950). Unraveling juvenile delinquency. New York: The Commonwealth Fund.

Harbison, J. (Ed.). (1983). Children of the troubles. Belfast: Stranmillas College.

Jamison, D. (1993). Touched with fire: Manicdepressive illness and the artistic temperament. New York: Free Press.

Kandel, E., Mednick, S. A., Kirkegaard-Sorensen, L., Hutchings, B., Knop, J., Rosenberg, R., \& Schulsinger, F. (1988). IQ as a protective factor for subjects at a high risk for antisocial behavior. Journal of Consulting and Clinical Psychology, 56, 224226.

Kraepelin, E. (1919). Dementia praecox and paraphrenia. Edinburgh, Scotland: Livingston.

Long, J. V. F., \& Vaillant, G. E. (1984). Natural history of male psychological health. XI: Escape from the underclass. American Journal of Psychiatry, $141,341-346$.

Luthar, S. S., \& Zigler, E. (1991). Vulnerability and competence: A review of research on resilience in childhood. American Journal of Orthopsychiatry, 61, 6-22.

Masten, A. (1989). Resilience in development: Implications of the study of successful adaptation for developmental psychopathology. In D. Cicchetti (Ed.), Rochester Symposium on Developmental Psychopathology, Vol. 1: The emergence of a discipline (pp. 261-294). Hillsdale, NJ: Erlbaum.

Meehl, P. E. (1973). Why I do not attend case conferences. In P. E. Meehl (Ed.), Psychodiagnosis: Selected papers (pp. 225-302). Minneapolis: University of Minnesota Press.

Monroe, S., \& Goldman, P. (1988). Brothers. New York: William Morrow.

Moskovitz, S. (1983). Love despite hate. New York: Schocken Books.

Neisser, U. (1986). The school achievement of minority children. Hillsdale, NJ: Erlbaum.

Pavenstedt, E. (1965). A comparison of the childrearing environment of upper-lower and very lowlower class families. American Journal of Orthopsychiatry, 35, 89-98.

Richters, J., \& Weintraub, S. (1990). Beyond diathesis: Toward an understanding of high risk environ- 
ments. In J. Rolf, A. S. Masten, D. Cicchetti, K. H. Nuechterlein, \& S. Weintraub (Eds.), Risk and protective factors in the development of psychopathology (pp. 67-96). New York: Cambridge University Press.

Rutter, M. (1987). Psychosocial resilience and protective mechanisms. American Journal of Orthopsychiatry, 57, 316-331.
Sroufe, L. A., \& Rutter, M. (1984). The domain of developmental psychopathology. Child Development, 55, 17-29.

Wolin, S. J., \& Wolin, S. (1993). The resilient self: How survivors of troubled families rise above adversity. New York: Villard Books.

Zigler, E., \& Glick, M. (1986). A developmental approach to adult psychopathology. New York: Wiley. 